\title{
NETWORK TOPOLOGY OF RENEWABLE ENERGY COMPANIES: MINIMAL SPANNING TREE AND SUB-DOMINANT ULTRAMETRIC FOR THE AMERICAN STOCK
}

\author{
Mansooreh KAZEMILARI ${ }^{1}$, Ali MOHAMADI ${ }^{1}$, \\ Abbas MARDANI ${ }^{*}$, Justas STREIMIKIS ${ }^{3}$ \\ ${ }^{1}$ Department of Management, School of Economics, Management \& Social Sciences, \\ Shiraz University, Shiraz, Iran \\ ${ }^{2}$ Azman Hashim International Business School, Universiti Teknologi Malaysia (UTM), \\ Skudai Johor, 81310, Malaysia \\ ${ }^{3}$ Lithuanian Institute of Agrarian Economics, V. Kudirkos g. 18-2, 03105 Vilnius, Lithuania
}

Received 07 September 2018; accepted 14 November 2018

\begin{abstract}
Renewable energy has become a significant market player after the turn of the millennium. Wind, solar, smart grid and further renewable energy stocks have experienced both serious up and down trends since that time. In this paper, computed the Minimal Spanning Tree (MST) and Sub-Dominant Ultrametric (SDU) for topological properties of what has been driving the price of renewable energy stock markets and sectors. In this regard, the main object is to define the similarity among sectors in financial market, which is statistically a multivariate time series. The principal mathematical tool to do macro analysis is multivariate vector correlation where multi-dimensional data is considered as a complex system. Furthermore, the base approach for filtering the significant information in a financial system is similarity network analysis. In this paper, the behavior of economic sectors of renewable energy played during $30^{\text {th }}$ July $2015-1^{\text {th }}$ January 2018 in America. Results of this study found that, solar sector in renewable energy is confirmed as the dominant sector in America during this period. In addition, results demonstrated that, the leader sector is Solar and the central hubs are Canadian Solar Inc. (CSIQ)from Solar and then Pattern Energy Group Inc. (PEGI)from Solar-Wind sectors.
\end{abstract}

Keywords: sector analysis, renewable energy, stock market, Similarity network analysis.

JEL Classification: Q2, D85, D53, B23.

\section{Introduction}

Energy technologies are clear sources of energy that have much lower environmental effects than conventional energy technologies. Researchers usually conduct renewable energy investments within the United States, often in the same state, and frequently in the same town

${ }^{\star}$ Corresponding author. E-mail: mabbas3@live.utm.my

This is an Open Access article distributed under the terms of the Creative Commons Attribution License (http://creativecommons. org/licenses/by/4.0/), which permits unrestricted use, distribution, and reproduction in any medium, provided the original author and source are credited. 
that is your energy dollars remain home to create job opportunities and fuel local economies rather than spending in other countries. In the meantime, renewable energy technologies expanded and made in the United States are being sold in foreign countries, providing an increase to the U.S. trade shortfall (Lyu \& Shi, 2018).

As one of the rapid increasing parts in the world economy, renewable energy is considered the leading position regarding both financial and environmental importance. This originates from the growing worries of continual climate change, energy sustainability, and technological progress (Jovovic, Simanaviciene, \& Dirma, 2017). As knowledge of the effects of pollution and the essential for a renewable energy in the near future increases, interest and investment in renewable energy will be on the rise, too (Chang \& Shieh, 2017).

In this regard, a few researchers studied on stock market analysis in renewable energy sector. In 2016, Mundada, Prehoda, \& Pearce (2016) studied on the estimation of U.S market for plug and play solar photovoltaic systems. Then, Zhang and Du (2017) investigate the dynamic relationships among the stock prices of new energy, fossil fuel and high technology companies in china. In 2018, Dutta, Bouri, and Noor (2018) investigated the link between the carbon emission and clean energy market. Stürmer, Novakovits, Luidolt, and Zweiler (2019) assessed the potentially available amount of methane from the existing plant stock within an Austrian region.

Nevertheless, it is important to study and know the influential stocks and sectors because savings and investment decisions without financial instruments regard for the opportunity cost of using those resources elsewhere in society is not possible (Zeng, Jiang, Ma, \& Su, 2018; Gormus, Soytas, \& Diltz, 2015). Moreover, the causality and the behavior of each sector and stock in the system is significant for predicting and signifying interruptions unfavorably impacting the steadiness in the world; and also in giving time sufficiently to response and provide resources for minimizing the impact in financial crises.

In financial market, stock market is known as a complex system with enormous interwoven relations among stock prices. The existence of interconnections is deemed as special characteristic in dynamics of financial market. Therefore, investigating the structure of such connections among sectors and stocks that are helpful to optimize the portfolio of assets as well as risk management is considered as a required issue. It has been stated that from a statistical physics outlook, correlation network analysis has developed in a variety of methods, such as Planar Maximally Filtered Graph (PMFG), Minimal Spanning Tree (MST) and correlation threshold method. Especially, as Mantegna (1999) first suggested the network analysis way of MST in stock market, technical correlation network widely used to examine the interactions of financial objects in a large number of financial markets.

Correlation structure is numerically formed a correlation matrix which is a random matrix (Rosenow, Gopikrishnan, Plerou, \& Stanley, 2003). As a random matrix, its important role can be found in various areas of scientific investigations; from soft sciences such as social network analysis (Freeman, 1977; Albert \& Barabási, 2002) until hard sciences like physics, especially econophysics (Mantegna \& Stanley, 2000; Eom, Oh, \& Kim, 2008). In those areas, we are dealing with time series of correlation matrix which becomes more complex if the number of variables becomes larger and the correlation structure becomes more challenging, and thus it becomes harder to understand (Mantegna \& Stanley, 2000). 
There are two major issues in stock network analysis. First, the appropriate model to explain stock price by measuring the similarities of time series. It is notable that each stock is customarily assumed to follow Geometric Brownian Motion (GBM) process. According to Ross (2011), the GBM process possesses neither the flaws of the Brownian Motion (BM) process when it is used in modeling the price of a security over time. This is because the use of logarithmic returns of stocks having non-negative share prices in the market, the properties of time independent and normally distributed. Therefore, we can say that the data governed by GBM law.

And the latter is searching for an appropriate method to summarize the structure of networks that graph theoretical method is recently applied to simplify the information included in stock networks controlled by GBM. Mantegna in 1999 applied the MST to investigate the topological properties and the related Sub Dominant Ultrametric (SDU) to comprehend the hierarchical tree (HT) of stocks. These days, the role of MST and SDU is applicable not only in various fields of finance, but also in a large number of areas of theoretical research. For example, see in foreign exchange (Wang, Xie, Han, \& Sun, 2012), general complex system (Tumminello, Aste, Di Matteo, \& Mantegna, 2005), economy analysis (Zhang et al., 2011a), portfolio analysis (Onnela, Chakraborti, Kaski, Kertesz, \& Kanto, 2003), risk assessment (Tola, Lillo, Gallegati, \& Mantegna, 2008), trading (Ulusoy et al., 2012) and volatility (Micciche, Bonanno, Lillo, \& Mantegna, 2003).

Great numbers of studies exist in the literature to analyze the similarity measure of stocks in the financial market. Understanding the relation and the role of stocks in these systems is vital. Although, the prior studies have little consideration the properties of stock networks for renewable energy companies by stock exchange. In financial network, the time series properties of stocks should be examined continuously since network structure changes with time. Whether the time series of stock' prices have the same structure compared to the prior studies is also an important query.

The primary objectives of this research can be described as follows:

i. Proposed MST and SDU to analyze the sectors behavior of stocks belongs in which the economic sector is composed of a number of homogenous stocks.

ii. Since each sector consists of a number of stocks, a method in multivariate case should be used. Hence, the focus of the present paper in a multivariate setting is on topological network analysis for sub-sectors of renewable energy.

iii. This paper focuses on the related stocks of clean energy firms and how the stock prices make the structure of inter-connections, reacts to other stocks, and the sectors that affect them.

According to above objectives, this study contributed the body of knowledge in the following directions:

i. This study, for the first time, integrated MST and SDU to network analysis of economic sectors in renewable energy by stock exchange to enrich the interpretation of intersectors by using Escoufier's coefficient.

ii. This study is considered sectors as a multidimensional entity of stock prices and uses $E V C$ to measure the similarity among sectors where each sector is represented as a multivariate time series of their related stock prices. 
The research progresses as follows. The following Section 1 is devoted to a review of Pearson correlation coefficient (PCC) as a common approach for constructing the correlation based network of stocks. And, in Section 2, we describe anew methodology to construct the sectors network of renewable energy. Section 3 presents the applications of the proposed methodology in stock market and economic sectors. We discuss the results obtained from topological network analysis. Finally, a brief summary and conclusion of the results and some directions for future research in last Section will be presented.

\section{Literature review}

Stock market is a significant part of the economy of a region. The stock market has a main role in the growth of the industry and commerce of the region that finally impacts the economy of the countries greatly. That is why the government, industry and even the central banks of the region observe the happenings of the stock market. The stock market is significant from both the industry's as well as the investor's view point.

This is the main function of the stock exchange; therefore, they play the most vital role of supporting the development of the industry and commerce in the region. That is why a stock market on the rise is the sign of a growing industrial division and a developing economy of the region.

Based on literature, companies inside developed markets mostly have a deeper relationship with their country than their division. Though, this is not always the situation. The level of contributions for various divisions and countries can differ extensively. Particularly, many researchers have found that there is a correlation between energy companies and the performance of their division worldwide. Considering a region that is composed of many stocks as a factor of regional financial market, we are interested to know how a sector affect and influence other sectors of renewable energy in America.

\subsection{Network construction of stocks}

In network-based approach, similarity-based network is a method to explore network properties form a similarity matrix with a special emphasis to correlation based network, i.e., network where the similarity measure is the linear cross correlation. The important example of similarity measure in univariate case is Pearson's correlation between stock $i$ and $j$. The basic cross correlation matrix formalism with details of two variables are as follows.

Network topology method is used to examine the interconnection of variables which is based on PCC-coefficient. It is shown that the PCC-coefficient can be used as a measure of similarity among the logarithm changes of stocks. Logarithmic returns refer to the changes of the logarithm of price, $V_{i}(T)=\ln Z_{i}(T+1)-\ln Z_{i}(T)$. Where $Z_{i}(T)$ denote the stock price (i) at time T. $i=1,2, \ldots, p$ and $p$ is the stocksnumber in which $p$ stocks are characterized by time series of its closing price. Pearson coefficient between the log returns of stock $i$ and $j$ is defined by

$$
P C_{i j}=\frac{Z_{i} Z_{j}-Z_{i} Z_{i j}}{\sqrt{Z_{i}^{2}-Z_{i}^{2}} \sqrt{Z_{j}^{2}-Z_{j}^{2}}},
$$


where $Z_{i}=\sum_{t=1}^{T} Z_{i}(t) / T$, is the statistical average of the time series over all the trading time $T$.

The structures of stocks are deemed as a complex system of inter relationship among stocks that can be shown as a correlation matrix PCC that is helpful to realize the behavior of stock network. PCC completely defines the structure of stock network which is a completely connected, weighted and undirected network with 60 nodes representing the stocks, and $60(60-1) / 2=1770$ inter node connections. Generally, a complete network on a graph with all the connections among nodes is an unreadable picture even for small networks. A more applicable method in this context is MST graph. To show the structures of 60 stocks based on PCC, network analysis can help us to simplify this network by using MST.

For this purpose, an appropriate algorithm can be employed. In this research, Kruskal algorithm is used as suggested by many researchers such as Wang et al. (2012), Brida and Risso (2010), Mantegna and Stanley (1999) and Mantegna and Stanley (2000). Kruskal's algorithm is applied to find MST. This technique is usually used in stock networks analysis. It proceeds by listing the distances in increasing order, and then choosing those links having the smallest distances, with the one restriction that we never want to get a cycle. This algorithm produces (59) number of links to be interacting between all the stocks (nodes). See Figure 1.

MST is usually used to summarize the complete network and filter the significant information. In this way, by using Matlab version R2011b and Pajek software, the simplified network can be visualized in the form of graphical representation which help to interpret the complex network of stocks. This is the common method to analyze the economic information in the stock market.

In next section, we describe network construction of sectors and the procedure of similarities network analysis based on Escoufier Vector Correlation (EVC) method in multivariate setting.

\section{Network construction of sectors}

The literature (Garas \& Argyrakis, 2007; Kantar, Keskin, \& Deviren, 2012; Tabak, Serra, \& Cajueiro, 2010) has indicated that the stocks in the same countries are homogenous in terms of their economic activities. However, those homogeneities cannot be applied to determine the correlation among economic sectors which are composed by a number of stocks. Therefore, the most important contribution of this study is to introduce multivariate vector correlation to define the correlation among sectors and analyze the topological structure of them.

This section considers the measure of correlation in multivariate setting. Since Hotelling's study (1936) on the measure of correlation among two multivariate sets, several measures were proposed. Cramer and Nicewander (1979) categorized them into two groups: first is the redundancy measurement which is related to predictability, and second is the measure of multivariate correlation in multivariate setting. The present research concerns the multivariate correlation measure and review its historical background. After Hotelling (1936) and Cramer and Nicewander (1979), several authors concerned on the measure of vector correlation, namely: Kshirsagar (1969), Coxhead (1974), Shaffer and Gillo (1974) and Cramer and Nicewander (1979). In most of these studies, the proposed correlation measures are a 
function of canonical correlation. This is a standard measure based on linear dependence of the random variables; CCA investigates linear indices between random vectors regarding the initial set that is perfectly correlated with a linear index of the random vectors regarding the second set. Masuyama (1941) also examined vector correlation in a different context. In this field, Escoufier (1973), Robert and Escoufier in (1976) and Stephens (1979) proposed a classical approach of linear multivariate statistical analysis as a multivariate vector correlation coefficient. It is a linear association which maximizes correlation coefficient under various sets of limitations.

In this research, the notion of multivariate vector correlation is defined followed the concept of similarity by using the EVC approach in multivariate setting. The similarity among multivariate setting in this approach can be introduce to construct similarities network based on the similarity among nodes that considered as random vector. In this study, it will be defined based on Escoufier's coefficient.

Suppose the random vector $K$ is a superposition of $m$ sub-vectors,

$$
K=\left(\begin{array}{c}
K^{(1)} \\
K^{(2)} \\
\vdots \\
K^{(m)}
\end{array}\right)
$$

where $K^{(1)}, K^{(2)}, \ldots, K^{(m)}$ are sub-vectors of dimension $p_{1}, p_{2}, \ldots, p_{m}$ with $p_{1}+p_{2}+\ldots+p_{m}=p$. For each $i$ and $j$ we write

$$
E\left(K^{(i)}\right)=\mu^{(i)}, \operatorname{COV}\left(K^{(i)}, K^{(j)}\right)=E\left(K^{(i)}-\mu^{(i)}\right)\left(K^{(j)}-\mu^{(j)}\right)^{t}=\Sigma_{i j} .
$$

If $m=2$, the mean is $\mu=\left(\begin{array}{l}\mu^{(1)} \\ \mu^{(2)}\end{array}\right)$ and covariance matrix of $K$ is $\Sigma=\left(\begin{array}{cc}\Sigma_{11} & \Sigma_{12} \\ \Sigma_{21} & \Sigma_{22}\end{array}\right)$.

Consider a random sample $K_{1}, K_{2}, \ldots, K_{n}$ taken from $K$ with $m=2$.

$$
K_{\alpha}=\left(\begin{array}{c}
K_{\alpha}^{(1)} \\
K_{\alpha}^{(2)}
\end{array}\right), \alpha=1,2, \ldots, n \text {. }
$$

The usual unbiased estimators for $\mu$ and $\Sigma$ are

$$
\bar{K}=\left(\begin{array}{l}
\bar{K}_{1} \\
\bar{K}_{2}
\end{array}\right) \text { and } S=\left(\begin{array}{ll}
S_{11} & S_{12} \\
S_{21} & S_{22}
\end{array}\right) .
$$

Here,

$$
\bar{K}^{(i)}=\frac{1}{n} \sum_{\alpha=1}^{n} K_{\alpha}^{(i)} \text { and } S_{i j}=\frac{1}{n-1} \sum_{\alpha=1}^{n}\left(K_{\alpha}^{(i)}-\bar{K}^{(i)}\right)\left(K_{\alpha}^{(j)}-\bar{K}^{(j)}\right)^{t} .
$$

Escoufier(1973) introduced the following measure of linear relationship of $K^{[1]}$ and $K^{[2]}$

$$
\rho \mathrm{v}=\frac{\operatorname{Tr}\left(\left(\Sigma_{12}\right)\left(\Sigma_{21}\right)\right)}{\left(\operatorname{Tr}\left(\Sigma_{11}^{2}\right) \operatorname{Tr}\left(\Sigma_{22}^{2}\right)\right)^{1 / 2}}
$$


Alternative expressions for $\rho v$ inits sample version can be written as:

$$
\rho V_{a b}=\frac{\operatorname{Tr}\left(\left(C O V_{a b}\right)\left(C O V_{b a}\right)\right)}{\left(\operatorname{Tr}\left(C_{a} V_{a a}^{2}\right) \operatorname{Tr}\left(C_{b b}^{2}\right)\right)^{1 / 2}},
$$

where $C O V_{a a}$ and $C O V_{b b}$ are the covariance of $p_{1}$ and $p_{2}$, respectively. And, $\left(C O V_{a b}\right)=\left(C O V_{b a}\right)^{t}$ (the transpose of $C O V_{a b}$ ) where $C O V_{a b}$ is the covariance of $p_{1}$ and $p_{2}$. $\rho v$ coefficient as a measure of similarity for two sets of $p_{1}$-dimension and $p_{2}$-dimension for the same sample, varying from 0 to 1 . The closer value of $\rho v$ to 1 means the better correlated of two sets of variables, the nearerthe two sample sets. By definition of $\rho$ v coefficient, the scale of similarity betweentwo sets takes values between zero and one.

The $\rho v$-correlation matrix as a similarity matrix in multivariate setting constructs a complex network between all multivariate sets of sectors in renewable energy. Then, topological network analysis is used to examine the interconnection of variables which is in terms of pv-coefficient. Furthermore, according to Zhang et al. (2011b) and Kazemilari and Djauhari (2015), the statistic of $\rho v$-coefficient is a good substitute for the PCC to measure the similarity of two variables. From this point of view, the relations of sectors can be measured by a $\rho v$ structure. In this research, the main objectives are to study economic sectors of renewable energy companies in terms of network topology by using the advantage of $\rho v$-coefficient in multivariate setting.

In general, topological network analysis starts with a matrix of $\rho \mathrm{v}$-coefficient as a measure of similarity. Then, the standard way is to transform it into dissimilarity matrix $D$ of $D=\left(d_{i j}\right)$, see Djauhari (2012). The matrix $D$, which satisfies (i) $d_{i j}=0$ if and only if $i=j$ and (ii) $d_{i j}=$ $d_{j i}$ represents a $\rho v$ network among variables to be analyzed. In order to extract a topological influence map of information in matrix of $\rho$, we construct a MST from $D$. As suggested in the literature, MST will be determined by using Kruskal's algorithm (Kruskal, 1956). From MST, we construct the network topology of all variables to simplify the information about $\rho v$ structure. The interpretation of network topology will be delivered by using the centrality measures. The details regarding those centralities can be seen for example, Newman (2005), Borgatti (2005) and Borgatti and Everett (2006).

\subsection{Dissimilarity}

Lots of discussions on the concepts of similarity and dissimilarity; the complementary to similarity are given by different authors. A high score of similarity measure shows that the two variables are strongly correlated, whereas a lower score demonstrates that there is less relations. Although, dissimilarity measure indicates opposite comment. A lower score shows more relationships, while a high score refers to negative relationships among variables.

By considering the correlations as their similarity coefficient $\rho v$ and a way to transform into dissimilarity coefficient $d$ the standard method in financial network analysis among financial objects is closely related to the Euclidean distance $d=\sqrt{2(1-\rho v)}$. 


\subsection{Data set of stocks and sectors}

This research is implemented using daily data of 60 stocks prices traded on the American renewable energy stock exchange from $30^{\text {th }}$ July 2015 to $1^{\text {th }}$ January 2018 . The data are collected from Yahoo Finance (n.d.). The stocks are categorized into different economic sectors. Those sectors occupied a large segment of the economy and refer to the number of stocks in a financial exchange. Those 60 stocks are subdivided into eleven groups sectors; Solar, Wind, Solar\& Wind, Solar\& Wind\& Hydroelectric, Solar\& Geothermal, General, Wave, Electric power, Fuel cell, Bio-fuel and Renewables. Appendix shows the list of stocks, corresponding countries and sectors which are provided in New York Stock Exchange [NYSE] (n.d.), Investopedia (2018) and Renewable Energy Word (2018).

This period has been chosen to cover more companies include General Electric Company (GE), Johnson Controls, Inc. (JCI), 3M company (MMM), Applied Materials, Inc. (AMAT), Tesla Motors Inc. (TESLA), Magna International, Inc. (MGA) that joined to utilize renewable energy technologies in many industries such as electricity generation, transportation, manufacturing, agriculture and energy system efficiency aftermath of the July 2015 . These renewable electricity generation technologies include photovoltaic or solar, wind turbine and geothermal.

\subsection{Topological properties}

When the similarity measure is clearly defined and the network has been made, what matters is to enrich the economic information by interpretation tools. The most fundamental theories in the network based approach in getting better visual insights and improving the economic interpretation's quality regarding the information gathered in the network, is centrality measure (Freeman, 1977, 1979; Borgatti, 2005). The importance of each item can be determined in terms of a measures of centrality to provide the result of role played for each particular item and to detect the influential items in the network (Espino \& Hoyos, 2010; Abbasi \& Altmann, 2011; Xu, Ma, Sun, Hao, Sun, \& Zhao, 2009) as recommended by Borgatti (2006, 2005), Sieczka and Holyst (2009), Park and Yilmaz (2010).

To the aid of interpretation of information contained in network, we conduct analysis based on degree of connections and betweenness centrality measure.

i. Degree of connection as a common concept is related to the connectivity of items that shows how many items are linked to the particular item. So, this measure represents the power of each node in influencing to the other nodes directly in terms of the number of links.

The degree of connection refers to the $a_{i j}$ is the $(i, j)$-th element of the adjacency matrix $A_{i j} . A_{i j}$ is a symmetric matrix consisting of elements of 0 and $1 . a_{i j}=1$ indicates the existence of relationship between a pair of items $i$ and $j$ in MST. In this regard, a stock of degree one (called leaf) is a worst performance stock in the market in terms of the number of other stocks being directly linked with.

ii. betweenness centralityis one of the most frequently considered centrality indices. Borgatti, Carley, and Krackhardt (2006) explored robustness of betweenness in graphs. 
Since a particular node is influential node if more nodes are connected to others through that node, so, it is necessary to define a measure of betweenness centrality to provide the result of role played for each node. It is most often applied in finding the links between two communities in a complex network (Newman, 2005) which is computed by:

$$
C_{b}=2 /(n-2)(n-1) \sum_{j, k \in V} \frac{d_{j k}(i)}{d_{j k}},
$$

where $d_{j k}$ refers tothe shortest paths between nodes $j$ and $k$, and $d_{j k}(i)$ is the number of those paths passed through $i$ (Freeman, 1977; Jang, Lee, \& Chang, 2011).

\section{Results}

\subsection{Network analysis of stocks: evidence from MST and SDU}

Before analyzing the network dynamics of the economic sectors, we first present the topological structure of stock network. In such manner, study uses the MST approach by applying Kruskal's algorithm and conducts analysis based on degree of connection and betweenness centrality measure which are defined in last section. In order to visualize that network topology, we use Pajek software that is mostly suggested for topological network analysis (Batagelj \& Mrvar, 2003, 2004; De Nooy, Mrvar, \& Batagelj, 2011). Figure 1 presents the correlationbased MST for the 60 stocks of eleven sectors of renewable energy. In this figure, stocks are colored based on the sector classification.

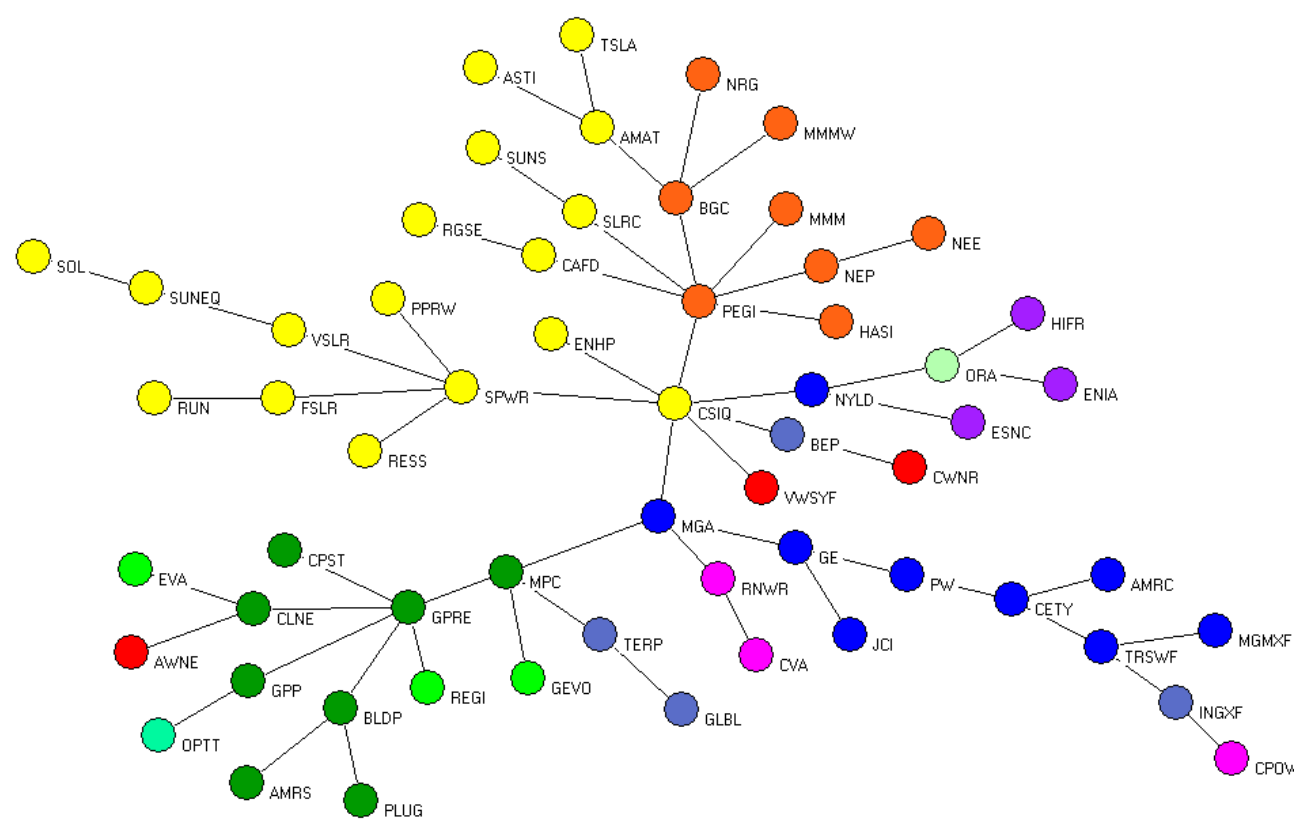

Figure 1. Network topology of 60stocks of renewable energy (source: authors' elaboration) 
Generally, Figure 1 indicates that the network mostly complemented with corresponding stocks from the same sectors such as Solar (yellow nodes), Solar \& Wind (orange nodes), Fuel and Bio-fuel (green nodes). However, there are some stocks in general (blue node), wind (red node) and electric power (purple node) that connected to the stocks of other sectors and mostly are linked with the stocks of Solar sector (yellow node).

Canadian Solar Inc. (CSIQ) occupies as central positions and most of stocks from different sectors connected to CSIQ. Canadian Solar Inc. (CSIQ) and Pattern Energy Group Inc. (PEGI) with highest linkage (7) are two influential stocks. The score of degree centrality (degree of connections) present the power of each stock to influence directly other stocks in term of the number of connections. These stocks have the highest scores based on betweenness centrality measuresand degree of connections and play the central level in the network. The top five stocks based on both centrality measures score are classified in Table 1.

Table 1. Five most important stocks and centrality measures (source: authors' elaboration)

\begin{tabular}{|l|l|c|c|}
\hline \multicolumn{1}{|c|}{ Stock } & \multicolumn{1}{|c|}{ Sector } & Degree & Betweenness \\
\hline Canadian Solar Inc. (CSIQ) & Solar & 7 & 0.71 \\
\hline Pattern Energy Group Inc. (PEGI) & Solar\& Wind & 7 & 0.42 \\
\hline Magna International, Inc. (MGA) & General & 4 & 0.61 \\
\hline Green Plains Inc. (GPRE) & Fuel cell & 6 & 0.31 \\
\hline Marathon Petroleum Corporation (MPC) & Fuel cell & 4 & 0.39 \\
\hline
\end{tabular}

CSIQ and PEGI are connected to all other stocks of their sectors in Solar (yellow nodes) and Solar \& Wind (orange nodes) sectors, respectively. The results show that Solar and Solar\& Wind are the two most influential sectors.

The MST provides the topological properties of the financial objects, and SDU is commonly regarded as a hierarchical tree (HT) presents the taxonomic information. Mantegna in 1999 provided an example of HT organization from MST. In financial market, the different correlation-based networks of the same total weight might be existed and they are associated with a unique HT. The construction of HT from MST can be used to reveal the cluster information in the network, however, MST just show the strongest connection of each stock. Therefore, clustering method is able to detect the minimum distance between the two linked stocks.

This approach is helpful to determine the particularly important underlying stock within sector $\mathrm{A}$ and within sector $\mathrm{B}$, which is indicative in making a connection between those sectors. Figure 2 shows the HT of 60 stocks.

In that figure, between two connected stocks $i$ and $j$ is a line in which the vertical line shows the distance $d_{i j}$. Figure 2 indicated that both CSIQ- SPWR $\left(d_{i j}=0.83\right)$ and SPWR$\operatorname{FSLR}\left(d_{i j}=0.86\right)$ from Solar sector are merged in the right cluster (highlighted yellow color) by shortest distances with strongest correlations, respectively. This indicates high rank of aggregation in Solar sector. 


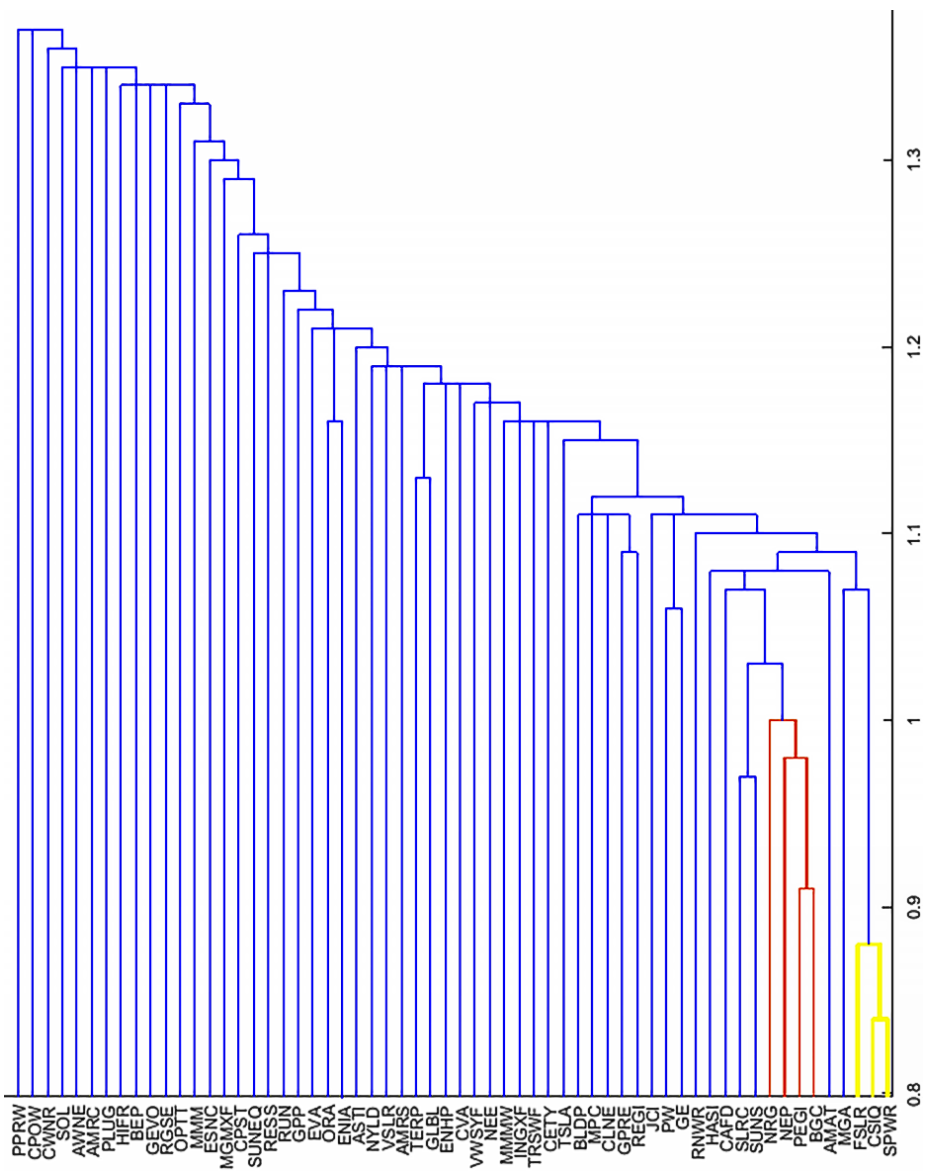

Figure 2. A history of sector clustering in terms of hierarchical tree (source: authors' elaboration)

\subsection{Network analysis of sectors: evidence from MST and SDU}

This section examines the topological network structure of sectors in multivariate setting. This approach helps to determine the underlying preferred sector. Figure 3 shows MST and HT of eleven sectors involves different number of stocks.

The sectors and their corresponding stocks in each sector are listed in Table 2.

The color of each node represents a sector and the values at the links are the distances between two sectors.

At a glance, we see at Figure 3 that the center of the network is dominated by Solar. The performance of this sector was dominant in renewable energy. Generally, the behavior of each sector in a network has its own features and the behavior will react the interconnections between it and other sectors. Based on the comparison of stock and sector network, it is evident that the stocks are likely to be merged to the same sectors.

By considering the MST, its related indexed HT revealed the hierarchical construction of the sectors in Figure 2. The HT and MST are used to determine the clusters of sectors. 

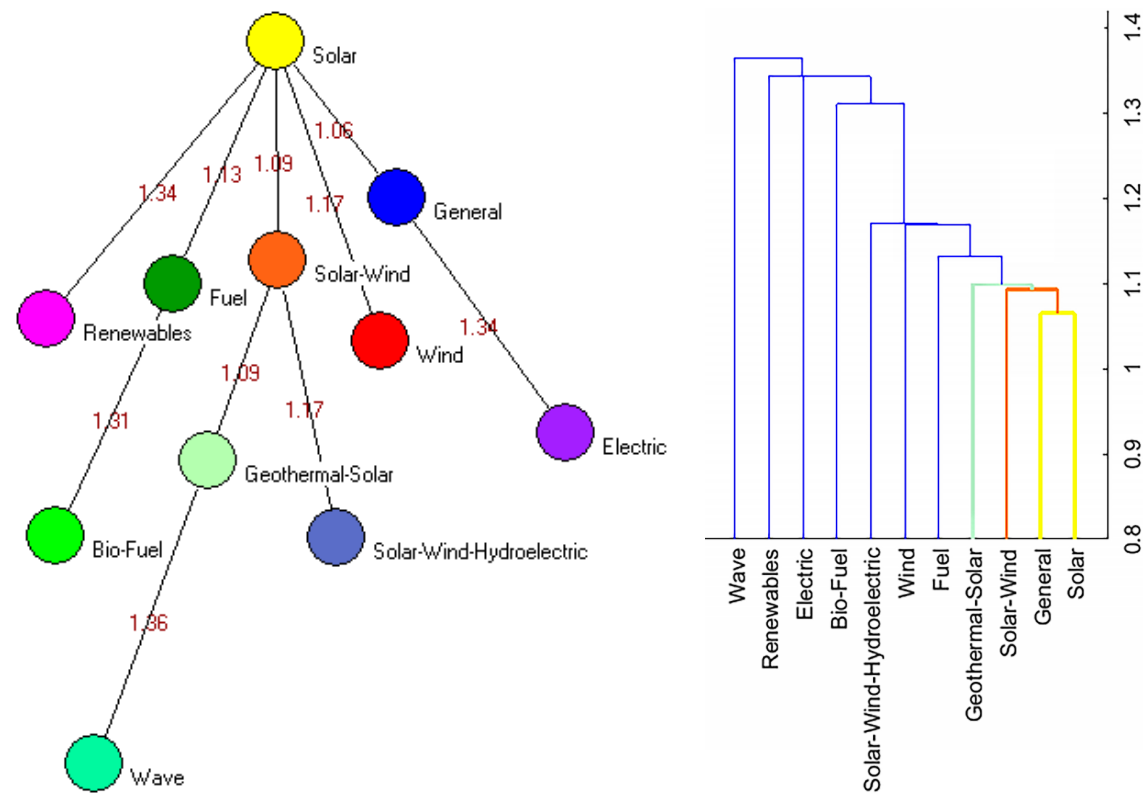

Figure 3. Topology network of sectors based MST and HT (source: authors' elaboration)

Table 2. List of sectors and their corresponding number of stocks (source: authors' elaboration)

\begin{tabular}{|c|l|c|}
\hline No. & \multicolumn{1}{|c|}{ Sector } & Number of stocks \\
\hline 1 & Solar & 17 \\
\hline 2 & Wind & 3 \\
\hline 3 & Solar\& Wind & 8 \\
\hline 4 & Solar\& Wind\& Hydroelectric & 4 \\
\hline 5 & Solar\& Geothermal & 1 \\
\hline 6 & General & 9 \\
\hline 7 & Electric power & 3 \\
\hline 8 & Wave & 1 \\
\hline 9 & Fuel Cell & 8 \\
\hline 10 & Bio-Fuel & 3 \\
\hline 11 & Renewables & 60 \\
\hline & Total & \\
\hline
\end{tabular}

In addition, the HT can be constructed directly. A significant feature is that the HT can be constructed directly and it is unique however MST might not be. The hierarchical and taxonomical structures of sectors in network are obtained in order to examine the interconnection of sectors by using SDU approach. For this purpose, the cluster of single linkage is applied to show the minimum distance. 
The figure shows that the distance among sectors mostly have high value. The Soalr General $\left(d_{a b}=1.06\right)$, Solar - Solar \& Wind $\left(d_{a b}=1.09\right)$ and Solar - Solar \& Geothermal $\left(d_{a b}=1.09\right)$ are linked with shortest distance (strong relationship), respectively.

From that figure, a cluster is clearly present Solar is the dominant sector. We also learn that Solar and Solar\& Wind are two prominent clusters. Previous study is also confirmed our result. Kazemilari, Mardani, Streimikiene, and Zavadskas (2017) detected General Cable Corporation (BGC) from Solar \& Wind sector as a leadership. However, under this study, leader sector is Solar and the central hubs are CSIQ from Solar and then PEGI from Solar $\&$ Wind sectors.

Figure 4 shows box plot of distance among sectors based on MST.

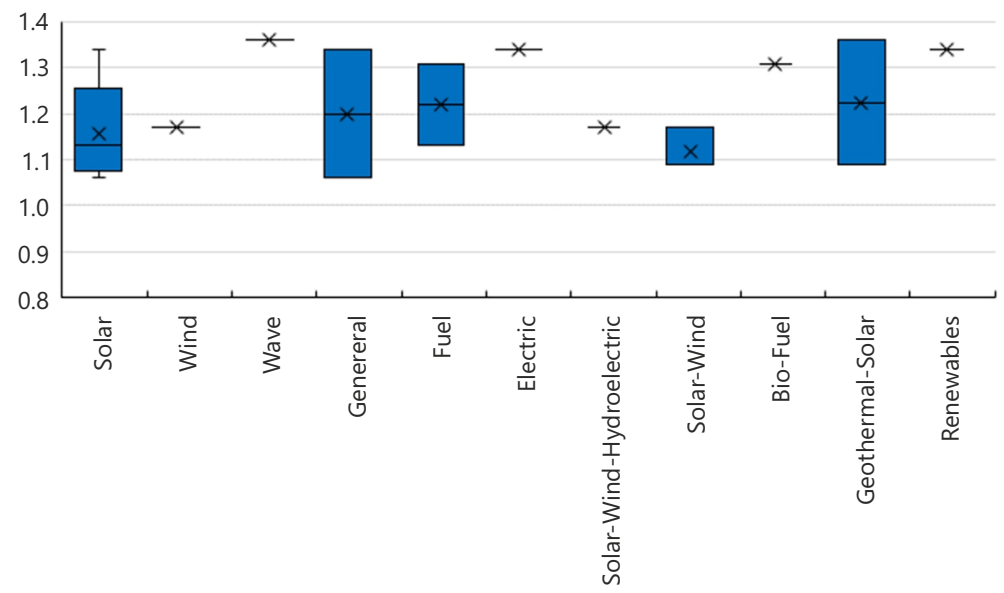

Figure 4. Box plot of distance between sectors based on MST (source: authors' elaboration)

This figure describes the use of the box plot chart to illustrate the distances of the sectors. It provides a useful way to visualize the range of distances for each sector. The line in the box denotes the mean of distance. Some sectors have just a star point in plot indicates that they have one connection (see degree of connection for each sector in Figure 3) and the distance of them are shown on the y-axis, for example Wind sector with $d=1.17$ and Wave sector with $d=1.36$. Wave sector with maximum distance among star points indicates a weaker relationship to connected Geothermal \& Solar sector.

The box plot is comparatively short (see Solar\& Wind) indicates that particular sector has similar distance to connected sectors. And the box plot is comparatively tall (see General and Geothermal \& Solar) denotes sector hold quite different distances in connection to other sectors.

It is also important to note that General Cable Corporation (BGC) was detected as a central hub in a priori research by Kazemilari et al. (2017) and Canadian Solar Inc. (CSIQ) was at the periphery systematically with worst performance. However, in this paper, BGC from Solar \& Wind sector was dominated by Pattern Energy Group Inc. (PEGI) in the same sector and Canadian Solar Inc. (CSIQ) from Solar sector hub. Some reasons of this observa- 


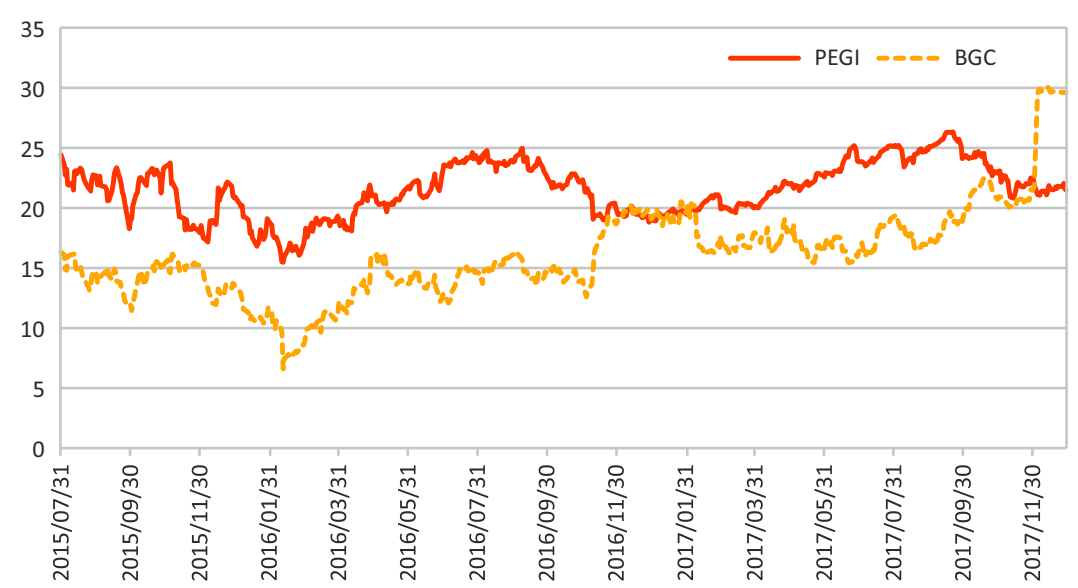

Figure 5. A history of price evolution for Pattern Energy Group Inc. (orange-full line) and General Cable Corporation (orange-dotted line) stocks (source: authors' elaboration)

tion consist of: The increase to utilize renewable energy technologies by more companies in comparison to the past. The work of Kwapień and Drożdż (2012) and Kazemilari et al. (2017) has been carried out for stocks in the world; however in this research only American companies have been involved. During the period, as shown in Figure 5, the performance of BGC is dominated by PEGI in the same sector. BGC has positive trend. However, its magnitude is less than PEGI before it rises on April 12, 2017.

\section{Conclusions}

This study has shed light to the sectors of renewable energy and its network analysis based on multivariate association when each sector is characterized as a multivariate time series of different number of stocks. It is valuable in its considerations of how the stocks in a sector affected the interrelationships of other stocks in particular sector. In this way, as a contribution of this study, a new structure of sectors in renewable energy as a multidimensional data of stocks based on network analysis is examined.

Generally, this research has focused on a network of stocks and sectors in renewable energy companies to show the mechanism of renewable energy in America. We presented the network topology among 60 stocks from $30^{\text {th }}$ July 2015 to $1^{\text {th }}$ January 2018 using the MST and SDU technique. In network topology and hierarchical cluster, the associations of stocks have tended to their related sectors. From the MST and hierarchical structure, the influenced stocks and sectors are determined. It is useful to ideas about the properties of sectors and their relationships. The dissimilarity measure represented as a distance between stocks in MST and hierarchical organization on the same model and purpose. In both methods, Solar and Solar\& Wind are the strongest and most influential sectors with smallest distance among stocks. This means that stocks in these sectors strongly related to one another. The major results of network topology can be summarized as follows:

From the hierarchical structure and MST, we conclude several some notable results. According to the overall centrality measure, Canadian Solar Inc. (CSIQ) and Pattern Energy 
Group Inc. (PEGI) are at the central hubs in network. These stocks are the strongest and most influential stocks. As summary, these stocks have more connections with the others; they are able to control the distribution of information in the network and are able to spread information quickly to the others. Solar sector in renewable energy is confirmed as the dominant sector in America during this period. However, this result may not stable in different time period. Based on the network topology of sectors, we learn that Solar - General, Solar - Solar \& Wind and Solar \& Wind-Solar \& Geothermal are more correlated than other sectors because of the similarities among them. Our result demonstrates that the network of sectors has a number of remarkable properties.

This research proposes fundamental plans to the interrelationship among stocks and the features of the sectors regarding the set of multidimensional information. Although, many analyses have been performed on stock markets, there is no attention considering the importance of the renewable energy sub-sectors in the world financial system. However, in accordance with the growth of renewable energy, multiple companies involved in these sectors have emerged. Their presence on stock exchanges worldwide has fueled the creation of indices that aims to track the performance of renewable; allowing us to analyze how sub sectors of renewable sector performs compared to others. With the growing frequency of renewable energy companies, this work suggests basic ideas about the relationship between sectors and the properties of the stock network in America. The outcomes of this study can be considered for forecasting and signaling disturbances that adversely affect the stability of the alternative energy companies, and giving alert to some companies especially in wave sector to pay more attention and expand renewable technologies with high priority sectors such as solar and solar-wind as findings of this study.

A great potential for future research is to integrate the EVC method with other possible complex network to examine the multi-dimensional network in other financial markets such as equity markets, commodity markets as well as FOREX market and stocks market. The method, based on the EVC coefficient, can be also combined with other network analysis approaches to study the topology of multi-dimensional networks.

\section{Acknowledgements}

The first author is supported by the National Elites foundation, Iran. The author gratefully acknowledges that sponsorship. The authors also thank Shiraz University for the opportunity to do this research.

\section{References}

Abbasi, A., \& Altmann, J. (2011). On the correlation between research performance and social network analysis measures applied to research collaboration networks. In $44^{\text {th }}$ Hawaii International Conference on System Sciences (HICSS), 4-7 January 2011, Kauai, HI, USA (pp. 1-10). IEEE. https://doi.org/10.1109/HICSS.2011.325

Albert, R., \& Barabási, A.-L. (2002). Statistical mechanics of complex networks. Reviews of Modern Physics, 74(1), 47. https://doi.org/10.1103/RevModPhys.74.47 
Batagelj, V., \& Mrvar, A. (2003). Density based approaches to network analysis - Analysis of Reuters terror news network. 20 p.

Batagelj, V., \& Mrvar, A. (2004). Pajekanalysis and visualization of large networks. Springer.

Borgatti, S. P. (2005). Centrality and network flow. Social Networks, 27(1), 55-71. https://doi.org/10.1016/j.socnet.2004.11.008

Borgatti, S. P. (2006). Identifying sets of key players in a social network. Computational \& Mathematical Organization Theory, 12(1), 21-34. https://doi.org/10.1007/s10588-006-7084-x

Borgatti, S. P., \& Everett, M. G. (2006). A Graph-theoretic perspective on centrality. Social Networks, 28(4), 466-484. https://doi.org/10.1016/j.socnet.2005.11.005

Borgatti, S. P., Carley, K. M., \& Krackhardt, D. (2006). On the robustness of centrality measures under conditions of imperfect data. Social Networks, 28(2), 124-136.

https://doi.org/10.1016/j.socnet.2005.05.001

Brida, J. G., \& Risso, W. A. (2010). Hierarchical structure of the German stock market. Expert Systems with Applications, 37(5), 3846-3852. https://doi.org/10.1016/j.eswa.2009.11.034

Chang, M.-Ch., \& Shieh, H.-Sh. (2017). The relations between energy efficiency and GDP in the Baltic Sea Region and Non-Baltic Sea Region. Transformations in Business \& Economics, 16(2(41), 235-247.

Coxhead, P. (1974). Measuring the relationship between two sets of variables. British Journal of Mathematical and Statistical Psychology, 27(2), 205-212. https://doi.org/10.1111/j.2044-8317.1974.tb00541.x

Cramer, E. M., \& Nicewander, W. A. (1979). Some symmetric, invariant measures of multivariate association. Psychometrika, 44(1), 43-54. https://doi.org/10.1007/BF02293783

De Nooy, W., Mrvar, A., \& Batagelj, V. (2011). Exploratory social network analysis with Pajek (Vol. 27). Cambridge University Press. https://doi.org/10.1017/CBO9780511996368

Djauhari, M. A. (2012). A robust filter in stock networks analysis. Physica A: Statistical Mechanics and its Applications, 391(20), 5049-5057. https://doi.org/10.1016/j.physa.2012.05.060

Dutta, A., Bouri, E., \& Noor, M. H. (2018). Return and volatility linkages between CO2 emission and clean energy stock prices. Energy, 164, 803-810. https://doi.org/10.1016/j.energy.2018.09.055

Eom, C., Oh, G., \& Kim, S. (2008). Statistical investigation on connected structure of stock networks in a financial time series. Korean Physical Society, 53, 3837-3841. https://doi.org/10.3938/jkps.53.3837

Escoufier, Y. (1973). Le traitement des variables vectorielles. Biometrics, 29(4), 751-760. https://doi.org/10.2307/2529140

Espino, J. M., \& Hoyos, J. R. C. (2010). Stability of centrality measures in social network analyses to identify long-lasting leaders from an indigenous boarding school of northern Mexico. Estudios Sobre las Culturas Contempor'aneas, 32, 155-171.

Freeman, L. C. (1977). A set of measures of centrality based on betweenness. Sociometry, 40(1), 35-41. https://doi.org/10.2307/3033543

Freeman, L. C. (1979). Centrality in social networks conceptual clarification. Social Networks, 1(3), 215-239. https://doi.org/10.1016/0378-8733(78)90021-7

Garas, A., \& Argyrakis, P. (2007). Correlation study of the Athens stock exchange. Physica A: Statistical Mechanics and its Applications, 380, 399-410. https://doi.org/10.1016/j.physa.2007.02.097

Gormus, N. A., Soytas, U., \& Diltz, J. D. (2015). Oil prices, fossil-fuel stocks and alternative energy stocks. International Journal of Economics and Finance, 7(7), 43-55. https://doi.org/10.5539/ijef.v7n7p43

Hotelling, H. (1936). Relations between two sets of variates. Biometrika, 28(3-4), 321-377. https://doi.org/10.1093/biomet/28.3-4.321

Investopedia. (2018). Retrieved from https://www.investopedia.com 
Jang, W., Lee, J., \& Chang, W. (2011). Currency crises and the evolution of foreign exchange market: Evidence from minimum spanning tree. Physica A: Statistical Mechanics and its Applications, 390(4), 707-718. https://doi.org/10.1016/j.physa.2010.10.028

Jovovic, R., Simanaviciene, Z., \& Dirma, V. (2017). Assessment of heat production savings resulting from replacement of gas with biofuels. Transformations in Business \& Economics, 16(1), 34-51.

Kantar, E., Keskin, M., \& Deviren, B. (2012). Analysis of the effects of the global financial crisis on the Turkish economy, using hierarchical methods. Physica A: Statistical Mechanics and its Applications, 391(7), 2342-2352. https://doi.org/10.1016/j.physa.2011.12.014

Kazemilari, M., \& Djauhari, M. A. (2015). Correlation network analysis for multi-dimensional data in stocks market. Physica A: Statistical Mechanics and its Applications, 429, 62-75. https://doi.org/10.1016/j.physa.2015.02.052

Kazemilari, M., Mardani, A., Streimikiene, D., \& Zavadskas, E. K. (2017). An overview of renewable energy companies in stock exchange: Evidence from minimal spanning tree approach. Renewable Energy, 102(Part A), 107-117. https://doi.org/10.1016/j.renene.2016.10.029

Kruskal, J. B. (1956). On the shortest spanning subtree of a graph and the traveling salesman problem. Proceedings of the American Mathematical Society, 7(1), 48-50. https://doi.org/10.1090/S0002-9939-1956-0078686-7

Kshirsagar, A. (1969). Correlation between two vector variables. Journal of the Royal Statistical Society. Series B (Methodological), 31(3), 477-485. https://doi.org/10.1111/j.2517-6161.1969.tb00807.x

Kwapień, J, \& Drożdż, S. (2012). Physical approach to complex systems. Physics Reports, 515(3), 115226. https://doi.org/10.1016/j.physrep.2012.01.007

Lyu, X., \& Shi, A. (2018). Research on the renewable energy industry financing efficiency assessment and mode selection. Sustainability, 10(1), 222. https://doi.org/10.3390/su10010222

Mantegna, R. N. (1999). Hierarchical structure in financial markets. The European Physical Journal B-Condensed Matter and Complex Systems, 11(1), 193-197. https://doi.org/10.1007/s100510050929

Mantegna, R. N., \& Stanley, H. E. (1999). Introduction to econophysics: correlations and complexity in finance. Cambridge University Press. https://doi.org/10.1017/CBO9780511755767

Mantegna, R., \& Stanley, H. E. (2000). An introduction to econophysics. Cambridge, MA: Cambridge University Press.

Masuyama, M. (1941). Correlation coefficient between two sets of complex vectors. Proceedings of the Physico-Mathematical Society of Japan. $3^{\text {rd }}$ Series 23, 918-924. https://doi.org/10.11429/ppmsj1919.23.0_918

Micciche, S., Bonanno, G., Lillo, F., \& Mantegna, R. N. (2003). Degree stability of a minimum spanning tree of price return and volatility. Physica A: Statistical Mechanics and its Applications, 324(1-2), 66-73. https://doi.org/10.1016/S0378-4371(03)00002-5

Mundada, A. S., Prehoda, E. W, Pearce, J. M. (2017). U. S. market for solar photovoltaic plug-and-play systems. Renewable Energy, 103, 255-264. https://doi.org/10.1016/j.renene.2016.11.034

Newman, M. E. (2005). A measure of betweenness centrality based on random walks. Social Networks, 27(1), 39-54. https://doi.org/10.1016/j.socnet.2004.11.009

New York Stock Exchange [NYSE]. (n.d.). Retrieved from www.nyse.com

Onnela, J.-P., Chakraborti, A., Kaski, K., Kertesz, J., \& Kanto, A. (2003). Dynamics of market correlations: Taxonomy and portfolio analysis. Physical Review E, 68(5), 056110. https://doi.org/10.1103/PhysRevE.68.056110

Park, K., \& Yilmaz, A. (2010, April 26-30). A social network analysis approach to analyze road networks. ASPRS Annual Conference (pp. 1-6). San Diego, California, CA.

Renewable Energy World. (2018). Renewable Energy News \& Information. Retrieved from https://www. renewableenergyworld.com 
Robert, P., \& Escoufier, Y. (1976). A unifying tool for linear multivariate statistical methods: the RVcoefficient. Applied Statistics, 25(3), 257-265. https://doi.org/10.2307/2347233

Rosenow, B., Gopikrishnan, P., Plerou, V., \& Stanley, H. E. (2003). Dynamics of cross-correlations in the stock market. Physica A: Statistical Mechanics and its Applications, 324(1), 241-246. https://doi.org/10.1016/S0378-4371(03)00005-0

Ross, S. M. (2011). An elementary introduction to mathematical finance. Cambridge University Press. https://doi.org/10.1017/CBO9780511921483

Shaffer, J. P., \& Gillo, M. W. (1974). A multivariate extension of the correlation ratio. Educational and Psychological Measurement, 34(3), 521-524. https://doi.org/10.1177/001316447403400305

Sieczka, P., \& Hołyst, J. A. (2009). Correlations in commodity markets. Physica A: Statistical Mechanics and its Applications, 388(8), 1621-1630. https://doi.org/10.1016/j.physa.2009.01.004

Stephens, M. (1979). Vector correlation. Biometrika, 66(1), 41-48. https://doi.org/10.1093/biomet/66.1.41

Stürmer, B., Novakovits, Ph., Luidolt, A., \& Zweiler, R. (2019). Potential of renewable methane by anaerobic digestion from existing plant stock - An economic reflection of an Austrian region. Renewable Energy, 130, 920-929. https://doi.org/10.1016/j.renene.2018.07.017

Tabak, B. M., Serra, T. R., \& Cajueiro, D. O. (2010). Topological properties of stock market networks: The case of Brazil. Physica A: Statistical Mechanics and its Applications, 389(16), 3240-3249. https://doi.org/10.1016/j.physa.2010.04.002

Tola, V., Lillo, F., Gallegati, M., \& Mantegna, R. N. (2008). Cluster analysis for portfolio optimization. Journal of Economic Dynamics and Control, 32(1), 235-258. https://doi.org/10.1016/j.jedc.2007.01.034

Tumminello, M., Aste, T., Di Matteo, T., \& Mantegna, R. N. (2005). A tool for filtering information in complex systems. Proceedings of the National Academy of Sciences of the United States of America, 102(30), 10421-10426. https://doi.org/10.1073/pnas.0500298102

Ulusoy, T., Keskin, M., Shirvani, A., Deviren, B., Kantar, E., \& D“onmez, C. C. (2012). Complexity of major UK companies between 2006 and 2010: Hierarchical structure method approach. Physica A: Statistical Mechanics and its Applications, 391(21), 5121-5131.

https://doi.org/10.1016/j.physa.2012.01.026

Wang, G.-J., Xie, C., Han, F., \& Sun, B. (2012). Similarity measure and topology evolution of foreign exchange markets using dynamic time warping method: Evidence from minimal spanning tree. Physica A: Statistical Mechanics and its Applications, 391(16), 4136-4146. https://doi.org/10.1016/j.physa.2012.03.036

Xu, Y., Ma, J., Sun, Y., Hao, J., Sun, Y., \& Zhao, Y. (2009). Using social network analysis as a strategy for e-commerce recommendation. PACIS 2009 Proceedings, 106. Retrieved from https://aisel.aisnet. org/pacis2009/106

Yahoo Finance. (n.d.). Retrieved from http://finance.yahoo.com

Zeng, S., Jiang, C., Ma, C., \& Su, B. (2018). Investment efficiency of the new energy industry in China. Energy Economics, 70, 536-544. https://doi.org/10.1016/j.eneco.2017.12.023

Zhang, G., \& Du, Z. (2017). Co-movements among the stock prices of new energy, high-technology and fossil fuel companies in China. Energy, 135, 249-256. https://doi.org/10.1016/j.energy.2017.06.103

Zhang, H., Zhang, X., Sun, Y., Liu, J., Li, W., \& Tian, J. (2011b). A weighted-RV method to detect finescale functional connectivity during resting state. NeuroImage, 54(4), 2885-2898. https://doi.org/10.1016/j.neuroimage.2010.10.051

Zhang, Y., Lee, G. H. T., Wong, J. C., Kok, J. L., Prusty, M., \& Cheong, S. A. (2011a). Will the US economy recover in 2010? A minimal spanning tree study. Physica A: Statistical Mechanics and its Applications, 390(11), 2020-2050. https://doi.org/10.1016/j.physa.2011.01.020 


\section{APPENDIX}

The list of renewable energy stocks, corresponding sectors and counties in America. Source: authors' elaboration

\begin{tabular}{|c|c|c|c|c|}
\hline \# & Symbol & Stock & Sector & Country \\
\hline 1 & BEP & Brookfield Renewable Partners L.P. & $\begin{array}{l}\text { Hydroelectric, Solar, } \\
\text { Wind }\end{array}$ & Hamilton, Bermuda \\
\hline 2 & ASTI & Ascent Solar Technologies, Inc. & Solar & Thornton, United States \\
\hline 3 & BLDP & Ballard Power Systems Inc. & Fuel Cells & Burnaby, Canada \\
\hline 4 & REGI & Renewable Energy Group, Inc. & Biofuel & Ames, United States \\
\hline 5 & FSLR & First Solar, Inc. & Solar & Tempe, United States \\
\hline 6 & GPRE & Green Plains Inc. (GPRE) & Biofuel & Omaha, United States \\
\hline 7 & INGXF & $\begin{array}{l}\text { Innergex Renewable Energy Inc. } \\
\text { (INGXF) }\end{array}$ & $\begin{array}{l}\text { Hydroelectric, Solar, } \\
\text { Wind }\end{array}$ & Longueuil, Canada \\
\hline 8 & SOL & ReneSola Ltd (SOL) & Solar & United States \\
\hline 9 & CWNR & $\begin{array}{l}\text { Crosswind Renewable Energy Corp. } \\
\text { (CWNR) }\end{array}$ & Wind & Naples, United States \\
\hline 10 & ORA & Ormat Technologies, Inc. (ORA) & Solar and Geothermal & Reno, United States \\
\hline 11 & RESS & $\begin{array}{l}\text { Renewable Energy Solution Systems, } \\
\text { Inc. (RESS) }\end{array}$ & Solar & Port Washington, United States \\
\hline 12 & ENHP & Enphase Energy, Inc. (ENHP) & Solar & California, United States \\
\hline 13 & GEVO & Gevo, Inc. (GEVO) & Biofuel & Colorado, United States \\
\hline 14 & SPWR & SunPower Corporation (SPWR) & Solar & California, United States \\
\hline 15 & RUN & Sunrun Inc. (RUN) & Solar & California, United States \\
\hline 16 & VSLR & Vivint Solar, Inc. (VSLR) & Solar & Lehi, Utah, United States \\
\hline 17 & NYLD & NRG Yield, Inc. (NYLD) & General & New Jersey, United States \\
\hline 18 & PEGI & Pattern Energy Group Inc. (PEGI) & Wind & California, United States \\
\hline 19 & VWSYF & Vestas Wind Systems (VWSYF) & Wind & $\begin{array}{l}\text { Central Denmark Region, } \\
\text { Denmark }\end{array}$ \\
\hline 20 & CAFD & 8point3 Energy Partners (CAFD) & Solar & California, United States \\
\hline 21 & CVA & Covanta Holding Corp. (CVA) & Renewables & New Jersey, United States \\
\hline 22 & EVA & Enviva Partners, LP (EVA) & Biofuel & Maryland, United States \\
\hline 23 & MGMXF & Alterra Power Corp. (MGMXF) & General & Vancouver, Canada \\
\hline 24 & RNWR & $\begin{array}{l}808 \text { Renewable Energy Corporation } \\
\text { (RNWR) }\end{array}$ & Renewables & $\begin{array}{l}\text { California \& the Western } \\
\text { United States }\end{array}$ \\
\hline 25 & PPRW & $\begin{array}{l}\text { Premier Power Renewable Energy, } \\
\text { Inc. (PPRW) }\end{array}$ & Solar & El Dorado Hills, Unitesstates \\
\hline 26 & SUNS & Solar Senior Capital Ltd. (SUNS) & Solar & New York, United States \\
\hline 27 & SLRC & Solar Capital Ltd. (SLRC) & Solar & New York, Unites States \\
\hline 28 & AWNE & $\begin{array}{l}\text { Americas Wind Energy Corporation } \\
\text { (AWNE) }\end{array}$ & Wind & Toronto, Canada \\
\hline 29 & RGSE & Real Goods Solar, Inc. (RGSE) & Solar & Colorado, United States \\
\hline
\end{tabular}


End of Appendix

\begin{tabular}{|c|c|c|c|c|}
\hline$\#$ & Symbol & Stock & Sector & Country \\
\hline 30 & AMRS & Amyris, Inc. (AMRS) & Fuel Cells & California, United States \\
\hline 31 & ENIA & Enel Américas S.A. (ENIA) & Electric power & Santiago, Chile \\
\hline 32 & BGC & General Cable Corporation (BGC) & Solar and Wind & Highland Heights, United States \\
\hline 33 & MMMW & $\begin{array}{l}\text { Mass Megawatts Wind Power Inc. } \\
(\mathrm{MMMW})\end{array}$ & Wind & Massachusetts, United States \\
\hline 34 & MPC & $\begin{array}{l}\text { Marathon Petroleum Corporation } \\
\text { (MPC) }\end{array}$ & Fuel Cells & Ohio, United States \\
\hline 35 & NEE & NextEra Energy, Inc. (NEE) & Solar and Wind & Florida, United States \\
\hline 36 & PLUG & Plug Power Inc. (PLUG) & Fuel Cells & New York, United States \\
\hline 37 & PW & Power REIT (PW) & General & United States of America \\
\hline 38 & SUNEQ & SunEdison, Inc. (SUNEQ) & Solar & Missouri, United States \\
\hline 39 & GLBL & TerraForm Global, Inc. (GLBL) & $\begin{array}{l}\text { Solar, Windand } \\
\text { Hydro-electric power }\end{array}$ & Maryland, United States \\
\hline 40 & TERP & TerraForm Power, Inc. (TERP) & $\begin{array}{l}\text { Solar, Windand } \\
\text { Hydro-electric power }\end{array}$ & Maryland, United States \\
\hline 41 & GE & General Electric Company & General & Massachusetts, United States \\
\hline 42 & JCI & Johnson Controls, Inc. & Solar & Wisconsin, United States \\
\hline 43 & MMM & 3M Company & Solar & Minnesota, United States \\
\hline 44 & AMAT & Applied Materials, Inc. & Solar & California, United States \\
\hline 45 & TSLA & Tesla Motors, Inc. & Solar & Palo Alto, United States \\
\hline 46 & MGA & Magna International, Inc. & General & Aurora, Canada \\
\hline 47 & HASI & $\begin{array}{l}\text { Hannon Armstrong Sustainable } \\
\text { Infrastructure Capital, Inc. (HASI) }\end{array}$ & Solar and Wind & Maryland, United States \\
\hline 48 & TRSWF & TransAlta Renewables Inc. (TRSWF) & General & Calgary, Canada \\
\hline 49 & GPP & Green Plains Partners, LP (GPP) & Fuel Cells & Nebraska, United States \\
\hline 50 & CLNE & Clean Energy Fuels Corp. (CLNE) & Fuel Cells & California, United States \\
\hline 51 & CETY & $\begin{array}{l}\text { Clean Energy Technologies, Inc. } \\
\text { (CETY) }\end{array}$ & General & California, United States \\
\hline 52 & ESNC & EnSync, Inc. (ESNC) & Electric power & Wisconsin, United States \\
\hline 53 & NRG & NRG Energy, Inc. (NRG) & Solar and Wind & Princeton, United States \\
\hline 54 & NEP & NextEra Energy Partners, LP (NEP) & Solar and Wind & Florida, United States \\
\hline 55 & HIFR & InfraREIT, Inc. (REIT) (HIFR) & Electric power & Dallas, United States \\
\hline 56 & AMRC & Ameresco, Inc. (AMRC) & General & Massachusetts, United States \\
\hline 57 & CPST & $\begin{array}{l}\text { Capstone Turbine Corporation } \\
\text { (CPST) }\end{array}$ & Fuel Cells & California, United States \\
\hline 58 & CSIQ & Canadian Solar Inc. & Solar & Guelph, Canada \\
\hline 59 & OPTT & $\begin{array}{l}\text { Ocean Power Technologies, Inc. } \\
\text { (OPTT) }\end{array}$ & Wave & $\begin{array}{l}\text { Monroe Township, United } \\
\text { States }\end{array}$ \\
\hline 60 & CPOW & Clean Power Concepts, Inc. (CPOW) & Renewable energy & Regina, Canada \\
\hline
\end{tabular}

